QUEIROZ, H. A.; ALVES, M. C.; SILVA, R. H. Qualidade dos solos de uma microbacia na região de Ilha Solteira - SP. Revista de Agricultura Neotropical, Cassilândia-MS, v. 1, n. 1, p. 26-37, jul./set. 2014.

\title{
QUALIDADE DOS SOLOS DE UMA MICROBACIA NA REGIÃO DE ILHA SOLTEIRA - SP
}

\section{HERNANDES ANDRADE QUEIROZ ${ }^{1}$, MARLENE CRISTINA ALVES ${ }^{2}$, HELIO RICARDO SILVA ${ }^{2}$}

${ }^{1}$ UNESP/Ilha Solteira-SP.langoisa@gmail.com, $\quad{ }^{2}$ Docentes/UNESP/Ilha $\quad$ Solteira-SP. mcalves.agr.feis.unesp.br, hrsilva@agr.feis.unesp.br

RESUMO: É inquestionável a degradação de mananciais devido à erosão e a poluição, decorrentes do desenvolvimento econômico. Neste sentido este trabalho teve como objetivos caracterizar a fisiografia e alguns atributos físicos dos principais solos de uma microbacia na cidade de Ilha Solteira, São Paulo. Foram utilizadas imagens de satélite de alta resolução 0,6 $\mathrm{m}$ Quickbird e o programa SPRING versão 4.3. Utilizando a metodologia de topossequência em relação à vertente, em cinco transectos com pontos locados no sentido do espigão até a foz, foram realizadas coletas de amostras de solo para análise granulométrica, macroporosidade, microporosidade, porosidade total. Realizou-se a estatística descritiva. Os solos representativos da microbacia estudada foram: Latossolo Vermelho distrófico e Argissolo Vermelho-Amarelo eutrófico. O Latossolo apresentou-se com condições físicas mais degradadas tomando-se como indicador de qualidade a densidade do solo; já no Argissolo as mesmas foram melhores; a variabilidade dos atributos físicos estudados foram maiores no Latossolo Vermelho comparado ao Argissolo Vermelho-Amarelo.

PALAVRAS-CHAVE: manejo do solo, uso do solo, Quickbird, porosidade do solo.

\section{SOIL QUALITY IN A WATERSHED AREA OF ILHA SOLTEIRA - SP}

\begin{abstract}
It is unquestionable the degradation of water sources due to erosion and pollution arising from economic development. In this sense this study aimed to characterize the physiography and some physical properties of the major soils of a watershed in the city of Ilha Solteira - São Paulo state, Brazil. High resolution satellite images of Quickbird $0.6 \mathrm{~m}$ and SPRING program version 4.3 were used. Using the methodology of topossequence for strand in 5 transects leased points towards the spigot to the mouth, collection of soil samples for particle size analysis, macroporosity, microporosity, total porosity were performed. It was conducted descriptive statistics. Representative soils from the watershed were studied: Hapludox Claysoil Red Yellow eutrophic. The Oxisol presented more degraded physical conditions taking into account the soil density as indicator of quality, whereas in Argisol this indicator performed better, the studied physical attributes variability were higher in Typic than in Red-Yellow Podzolic.
\end{abstract}

KEYWORDS: soil management, land use, Quickbird, soil porosity

\section{INTRODUÇÃO}

A utilização e o manejo inadequados dos recursos naturais, o predomínio da pecuária extensiva, a elevada concentração da propriedade da terra, o intenso êxodo rural e as grandes dificuldades enfrentadas pelos pequenos produtores na área de influência dos reservatórios 
das Usinas Hidrelétricas do Complexo Urubupungá, despertam os interesses de pesquisadores que procuram indicar soluções para reverter ou pelo menos amenizar o grave quadro econômico, social e ambiental existente nos municípios desta região. Segundo Santos et al. (2007), as intervenções numa bacia, se apoiadas na inter-relação de aspectos básicos como o econômico, ambiental e cultural, interferem significativamente no grau de organização dos proprietários das terras e moradores.

As bacias hidrográficas têm a área da superfície terrestre drenada por um rio principal, limitado por divisores de água, desempenhando um papel para transporte de diversos materiais e sedimentos para o rio principal, sendo um fator natural ou antrópico, modelando a paisagem. O mapeamento de uma microbacia permite uma pesquisa mais ampliada dos aspectos das condições de recursos naturais, tendo como ponto de vista um planejamento das atividades rurais e urbanas destas microbacias.

A dinâmica de uso e ocupação do solo em bacias hidrográficas exige estudos para a compreensão dos diversos impactos provocados pela ação antrópica e estratégias adequadas para a conservação dos recursos naturais nestas áreas. Os principais impactos ocasionados por modificações no uso e cobertura do solo em microbacias são: a redução da capacidade de infiltração, o aumento do escoamento superficial e erosão, a sedimentação dos cursos d'água, a diminuição da profundidade do leito dos cursos d'água e consequentemente o aumento de cheias e inundações. Neste sentido, diversos diagnósticos integrados podem ser utilizados, todavia, o físico-conservacionista, socioeconômico e do saneamento ambiental se destacam, pois, além de serem quantitativos, são prioritários e fundamentais (ROCHA, 1997).

A compactação do solo é um processo de densificação, no qual há um aumento da resistência à penetração no solo e redução da porosidade total, da macroporosidade, da permeabilidade e da infiltração de água, resultantes de cargas aplicadas na superfície do solo (SOANE; OUWERKERK, 1994). Além das consequências para a conservação dos solos, o adensamento e a baixa infiltração de água no solo tornam as plantas mais suscetíveis a déficits hídricos e com limitada capacidade de absorver nutrientes em camadas subsuperficiais (ROSOLEM et al., 1994).

Rocha e Daltrozo (2008) relataram que o diagnóstico físico conservacionista destacase, pois contribui para a utilização racional e sustentável dos recursos naturais renováveis através do estudo das características físicas da terra. A informação fornecida por este diagnóstico permite a formulação de medidas pertinentes de controle da erosão e de cheias, prevenção contra secas, controle das atividades agrícolas e pecuárias e planejamento e localização espacial das ações de florestamento.

A infiltração de água no solo é um fator que indica as condições físicas do solo. Num estudo em um Latossolo Vermelho-Escuro sob preparo convencional, cultivo mínimo e sistema de plantio direto, Barcelos et al. (1999) verificaram que os preparos conservacionistas de solo (sistema de plantio direto e cultivo mínimo) apresentaram taxas de infiltração de água no solo superiores às do preparo convencional, exceto no período imediatamente após o preparo de solo. Alves et al. (2005) verificaram que, em função dos efeitos ocasionados no solo, o preparo convencional promoveu alterações nas suas propriedades físicas e na taxa de infiltração de água comparativamente ao solo sob mata nativa. Isto reflete em maior escoamento superficial e maiores perdas de solo por erosão.

Neste sentido este trabalho teve por objetivo efetuar a caracterização fisiográfica e de alguns atributos físicos dos principais solos da Microbacia Jardim Novo Horizonte, na cidade de Ilha Solteira, São Paulo. Este estudo dará subsídios para a identificação de áreas de riscos quanto à erosão e poluição dos mananciais de água e do atual estágio de degradação dos solos 
que compõem a microbacia.

\section{MATERIAL E MÉTODOS}

O município de Ilha Solteira está localizado a uma latitude $20^{\circ} 25^{\prime} 58^{\prime \prime}$ sul e a uma longitude 51²0'33" oeste, noroeste do Estado de São Paulo, na posição mais estratégica da Hidrovia Tietê-Paraná, sendo cortado pelo rio São José dos Dourados que está ligado pelo canal de Pereira Barreto ao rio Tietê e ambos desaguando no rio Paraná dão a esta região um aspecto de ilha gigantesca (Figura 1).

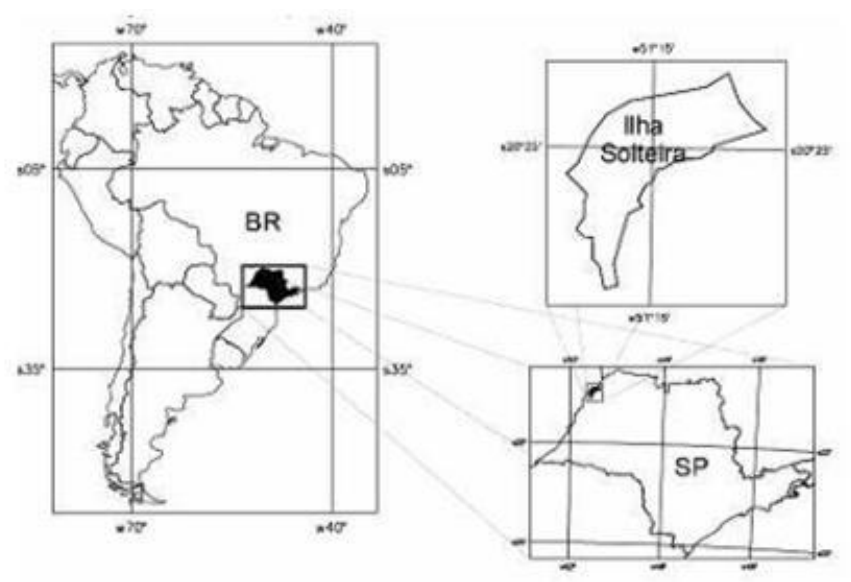

Figura 1. Mapa da localização do Brasil, do estado de São Paulo e do município de Ilha Solteira.

O clima da cidade de Ilha Solteira, segundo a classificação de Koppen, é do tipo Aw, tropical úmido e, ainda, caracteriza- se por apresentar uma estação chuvosa no verão e seca no inverno, com uma temperatura média de $24,5^{\circ} \mathrm{C}$, precipitação média anual de $1.232 \mathrm{~mm}$ e umidade relativa média anual de 64,8\% (HERNANDEZ et al., 1995).

O método utilizado para locar os pontos de coleta de solos foi o de adequar linhas em transversal a microbacia no sentido vertente, chamado de "transecto". Para isso foi considerado o menor transecto aquele cuja distância de um divisor de água a outro foi menor, sendo neste caso a distância de $1.310 \mathrm{~m}$. Os pontos foram localizados por meio do programa SPRING no item distância em metros. Os transectos indicaram a rota de caminho na vertente, sempre começando nas partes altas das vertentes (Figura 2). Estipulou-se no mínimo 20 pontos de amostragens por transecto, portanto, a distância entre eles foi de 65,5 metros (1.310 $\mathrm{m}$ dividido por 20 pontos). O número de pontos dos transectos foram diferentes devido à irregularidade natural da microbacia, tendo divisores de água distante um do outro. Nos últimos transectos há menor quantidade de pontos por estar na foz, pois há diminuição de vertentes havendo aplainamento e o afinamento entre a distância das mesmas, diminuindo a declividade da vertente e diminuindo o declive perante o Rio Paraná (Figura 2). No último transecto, próximo a foz tem-se o número mínimo de pontos (20).

Os tipos de solos mais representativos da Microbacia Jardim Novo Horizonte estão representados na Figura 3. Verificou-se que $70 \%$ da área está representada pelo Latossolo Vermelho distroférrico e $30 \%$ pelo Argissolo Vermelho-Amarelo eutrófico.

Uma das etapas que ocorreu a construção de uma base cartográfica da área de estudo, utilizando o Sistema de Informações Geográficas - SPRING versão 4.3/INPE. Nesta etapa foi 
realizada a importação da imagem de sensoriamento remoto de formato digital e conversão para o sistema de projeção cartográfico adotado (UTM/SAD69).

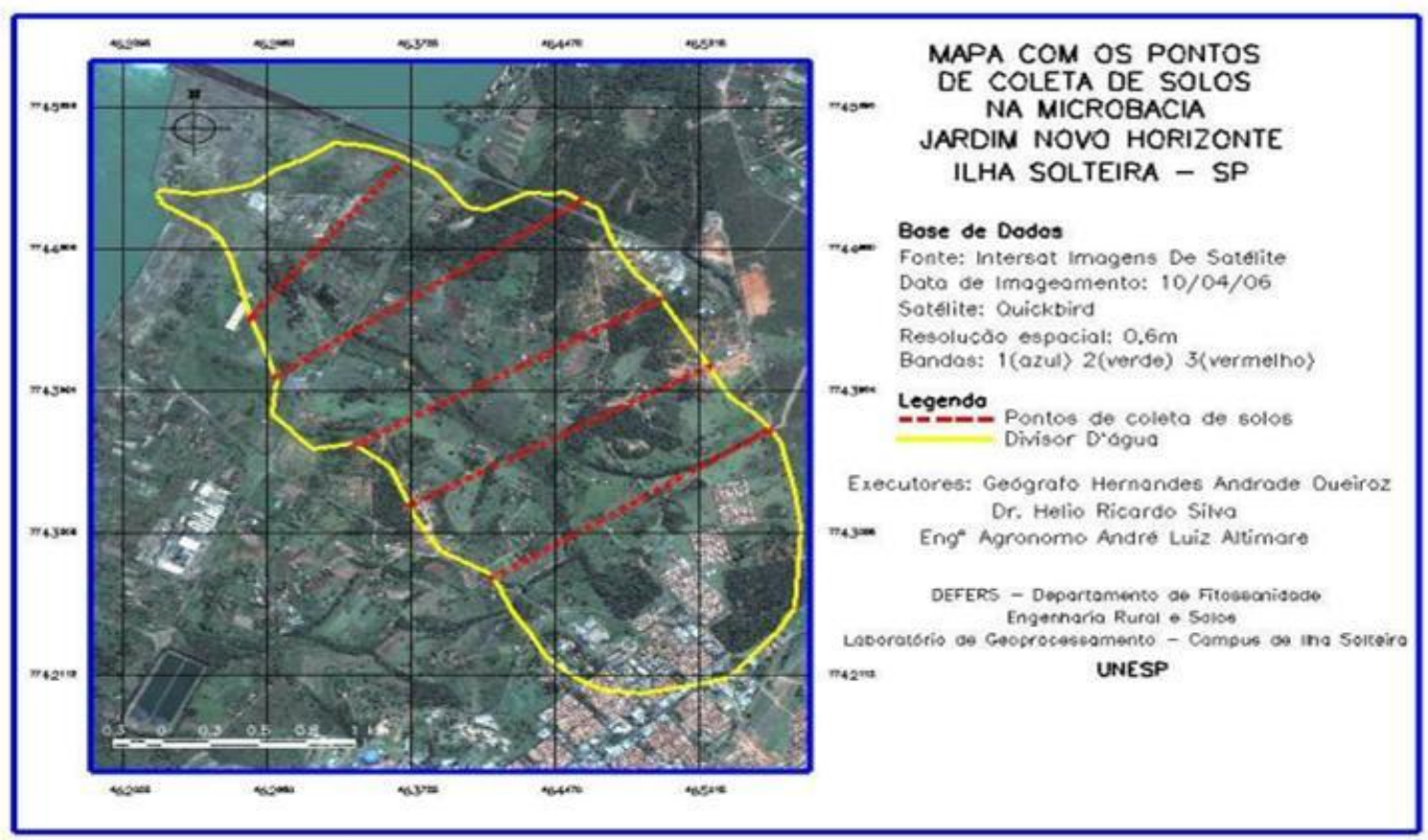

Figura 2. Carta imagem da Microbacia Jardim Novo Horizonte com a localização dos pontos de coletas de solos.

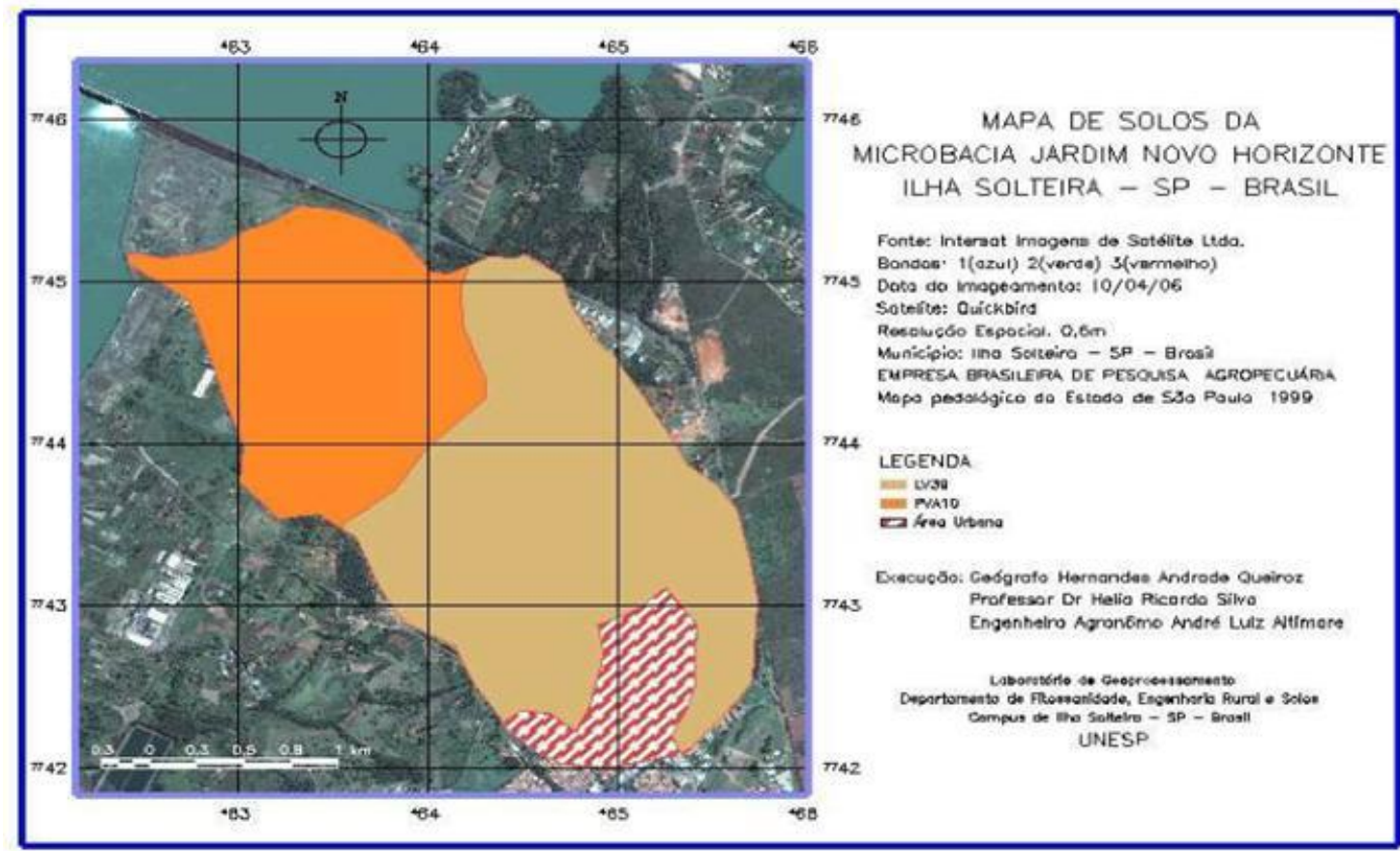

Figura 3. Mapa Pedológico da Microbacia Jardim Novo Horizonte, Ilha Solteira, SP.

$\mathrm{Na}$ etapa seguinte, por meio do método das chaves, foi realizada a fotointerpretação da composição colorida 1(B) 2(G) 3(R) da imagem QUICKBIRD de 10/04/2006 diretamente na tela 1 do monitor do computador, sendo acopladas as telas 2 e 3 que foram carregadas com as bandas monocromáticas 2 e 3 . Durante esta atividade foi utilizada a função de processamento das imagens (ampliação de contraste) possibilitando a melhor definição e facilitando a digitalização das classes predominantes analisadas. A delimitação das classes foi realizada por 
digitalização manual à medida que foram sendo identificadas no processo de interpretação pelas funções de Edição Vetorial.

O produto obtido foi uma carta imagem preliminar contendo os polígonos para uso e ocupação do solo e cores selecionadas para cada tipo de uso do solo. Em seguida foi realizado um trabalho de campo na microbacia com o objetivo de descrição das classes de uso/cobertura do solo destes polígonos. Durante a campanha de campo, todos estes locais visitados foram descritos e fotografados. Posteriormente, foi realizada nova fotointerpretação, considerando os dados coletados no campo, algumas classes foram reagrupadas. Na última etapa foram geradas a Carta Imagem drenagem, uso e Ocupação do solo e definidos os pontos para realização de coletas de solos e testes de infiltração.

Os pontos para as medições de infiltração de água no solo foram escolhidos no $1^{\circ}$ e $5^{\circ}$ transectos; o $1^{\circ}$ começando na parte mais alta do perfil longitudinal da drenagem, e o $5^{\circ}$ na parte mais baixa, no sentindo transversal inserindo os pontos das medições da infiltração. Foram locados 13 pontos; sete no transecto 1 e seis no transecto 5 . No transecto 1 foi encontradoo Latossolo Vermelho, e no transecto 5 o solo predominante é Argissolo Vermelho-Amarelo na parte baixa do perfil longitudinal, sentido da foz da drenagem da microbacia Figura 4.

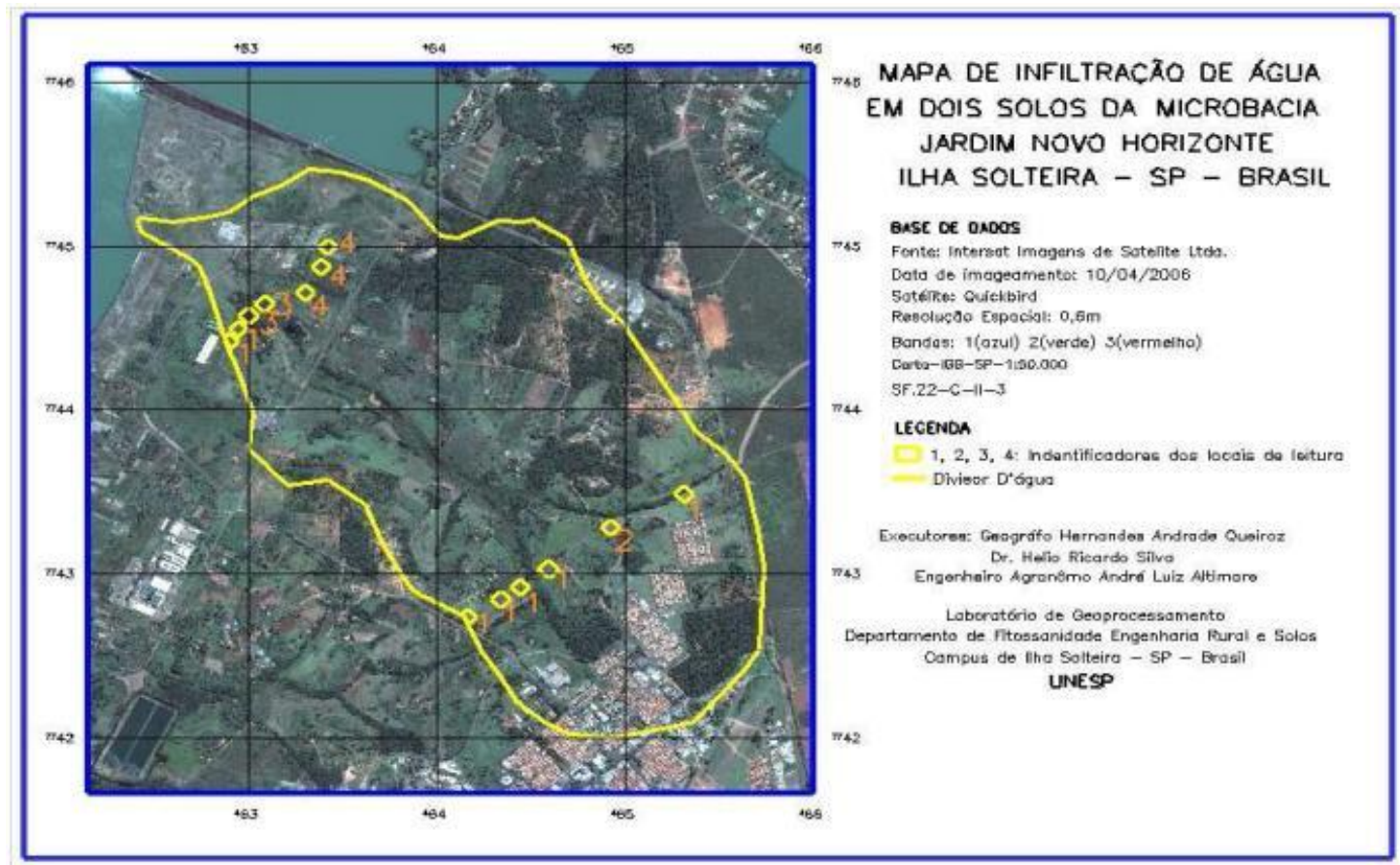

Figura 4. Carta imagem da Microbacia Jardim Novo Horizonte com a localização dos pontos de medições da infiltração de água no solo

As propriedades físicas do solo analisadas de cada ponto amostral (Figura 2: pontos em vermelho) foram: porosidade total, pelo método do anel volumétrico; microporosidade, pelo método da mesa de tensão com coluna de água de $60 \mathrm{~cm}$; macroporosidade, por diferença entre a porosidade total e a microporosidade; textura do solo utilizando-se o método da pipeta. Todos os métodos foram realizados de acordo com parâmetros Embrapa (1997). A medição da taxa de infiltração de água no solo foi realizada empregando-se o método dos anéis concêntricos (BERTRAND, 1965). Utilizou-se o modelo matemático de Smith (1972) equação (1) para descrever a taxa de infiltração, cuja fórmula é: 
$\mathrm{I}=\mathrm{a} \mathrm{t}^{\mathrm{b}}+\mathrm{c}$

Sendo, $\mathrm{I}=$ taxa de infiltração de água $\left(\mathrm{cm} \mathrm{h}^{-1}\right)$, a e $\mathrm{b}=$ coeficiente de ajuste do modelo, $\mathrm{c}=$ taxa constante de infiltração de água $\left(\mathrm{cm} \mathrm{h}^{-1}\right), \mathrm{t}=$ tempo $(\min )$ e tb taxa de infiltração

Os resultados foram analisados efetuando-se a estatística descritiva, utilizando o programa SAS.

\section{RESULTADOS E DISCUSSÃO}

Na Tabela 1 têm-se os resultados da análise descritiva para as propriedades físicas estudadas. Verificou-se que a média da macroporosidade foi igual nos dois tipos de solos encontrados na microbacia e também para as duas profundidades analisadas. Porém, para o Latossolo Vermelho a variância e o coeficiente de variação, na profundidade de $0,00-0,10 \mathrm{~m}$, foram maiores entre as profundidades do mesmo solo e, entre os solos. Isto ocorreu provavelmente devido ao tipo de uso no Latossolo Vermelho, o qual predominou culturas anuais e pastagens.

A dependência espacial da taxa de infiltração de água no solo é atribuída não apenas a processos de formação do solo, mas também a seus sistemas de manejo. Além disso, trata-se de um parâmetro com alta variabilidade espacial (VIEIRA et al., 1981) e, em pastagens, o hábito de pastejo do gado pode ser uma das causas para isso.

A maior variabilidade ocorre nos solos utilizados com manejo e os riscos de degradação também se dão na camada superficial devido ao preparo do solo. Desta forma, tanto o impacto das gotas de chuva quanto a enxurrada contribuem para modificar as condições físicas da superfície do solo, alterando a rugosidade superficial, a porosidade e a taxa de infiltração de água. O efeito da cobertura do solo na redução da velocidade do escoamento superficial da água é explicado pela tortuosidade dos caminhos a serem percorridos pelo fluxo, imposta pelos resíduos, bem como pela barreira física proporcionada pelos resíduos vegetais, impedindo o livre escoamento da água, sendo que esta redução é tanto maior quanto maior for a quantidade de resíduos vegetais ou culturais na superfície Carvalho et al. (1990). Já para o Argissolo Vermelho o coeficiente de variação foi igual nas duas profundidades estudadas e a variância da amostragem foi menor comparada com o Latossolo. Ressalta-se que neste tipo de solo predominou o uso com horticultura e silvicultura.

Para a média da microporosidade podem-se observar diferenças entre os tipos de solos, porém, o coeficiente de variação foi semelhante tanto entre os solos como entre as profundidades. A microporosidade foi maior no Argissolo, fato relacionado ao conteúdo de argila e silte serem maior neste solo. O que explica também o comportamento da porosidade total. Na caracterização da distribuição de tamanho de poros assim como na porosidade total, a maior variabilidade ocorreu para a macroporosidade. O coeficiente de variação para a macroporosidade foi o maior, sendo considerado alto (> $24 \%$ ) segundo Warrick e Nielsen (1980), enquanto que para a microporosidade e porosidade total foi médio (12-24\%). Além disso, os valores de macroporosidade estão no limite considerado críticos para o adequado desenvolvimento das culturas, que é de $0,10 \mathrm{~m}^{3} \mathrm{~m}^{-3}$ (GREENLAND, 1977). Estes resultados mostram que o solo está em processo de degradação que propicia a compactação, aumento do escoamento superficial e aparecimento de vários tipos de erosão. Pela própria natureza dos fatores responsáveis pela sua formação, o solo apresenta heterogeneidade, tanto vertical como horizontalmente. Este fato ocorre porque o próprio material de origem não é uniforme em 
toda a sua extensão, ou seja, o processo de intemperização não ocorre de forma homogênea e contínua. Segundo os princípios básicos da experimentação, a variabilidade do solo ocorre de forma aleatória.

Tabela 1. Estatística descritiva para os resultados da macroporosidade, microporosidade e porosidade total $\left(\mathrm{m}^{3} \mathrm{~m}^{-3}\right)$ e para as frações texturais $\left(\mathrm{g} \mathrm{kg}^{-1}\right)$, para os dois tipos de solos da Microbacia Jardim Novo Horizonte, Ilha Solteira, SP, na profundidade $0,00-0,10$ e $0,10-0,20 \mathrm{~m}$.

\begin{tabular}{|c|c|c|c|c|c|c|}
\hline \multirow{2}{*}{ Estatística } & \multicolumn{6}{|c|}{ Latossolo Vermelho } \\
\hline & Macroporosidade & Microporosidade & P. total & Argila & Areia & Silte \\
\hline \multicolumn{7}{|c|}{ Profundidade de $0,00-0,10 \mathrm{~m}$} \\
\hline Média & 0,10 & 0,28 & 0,38 & 141 & 757 & 102 \\
\hline Variância & 0,0032 & 0,0048 & 0,0031 & 659,40 & 1879,40 & 1069,80 \\
\hline $\begin{array}{l}\text { Desvio } \\
\text { padrão }\end{array}$ & 0,05 & 0,06 & 0,05 & 81,20 & 137,00 & 103,40 \\
\hline $\mathrm{CV} \% *$ & 50,00 & 21,42 & 13,51 & 57,58 & 18,10 & 101,17 \\
\hline Máximo & 0,26 & 0,44 & 0,59 & 469 & 914 & 762 \\
\hline Mínimo & 0,03 & 0,16 & 0,27 & 50 & 128 & 8 \\
\hline \multicolumn{7}{|c|}{ Profundidade de $0,10-0,20 \mathrm{~m}$} \\
\hline Média & 0,10 & 0,28 & 0,38 & 160 & 744 & 101 \\
\hline Variância & 0,0019 & 0,0047 & 0,0032 & 715,90 & 1292,30 & 394,90 \\
\hline $\begin{array}{l}\text { Desvio } \\
\text { padrão }\end{array}$ & 0,04 & 0,06 & 0,05 & 84,60 & 113,60 & 62,80 \\
\hline $\mathrm{CV} \% *$ & 40,00 & 21,42 & 13,51 & 52,85 & 15,28 & 62,13 \\
\hline Máximo & 0,21 & 0,50 & 0,56 & 530 & 937 & 344 \\
\hline Mínimo & 0,03 & 0,17 & 0,26 & 67 & 402 & 14 \\
\hline \multicolumn{7}{|c|}{ Argissolo Vermelho-Amarelo } \\
\hline \multicolumn{7}{|c|}{ Profundidade de $0,00-0,10 \mathrm{~m}$} \\
\hline Estatística & Macro & Micro & $\begin{array}{c}\text { Poros. } \\
\text { total }\end{array}$ & Argila & Areia & Silte \\
\hline Média & 0,10 & 0,39 & 0,49 & 243 & 534 & 223 \\
\hline Variância & 0,0018 & 0,0065 & 0,0123 & 1817,90 & 3780,00 & 887,10 \\
\hline $\begin{array}{l}\text { Desvio } \\
\text { padrão }\end{array}$ & 0,04 & 0,08 & 0,11 & 134,80 & 194,40 & 94,10 \\
\hline $\mathrm{CV} \% *$ & 40,00 & 20,51 & 22,91 & 55,56 & 36,38 & 42,04 \\
\hline Máximo & 0,20 & 0,55 & 0,70 & 616 & 938 & 411 \\
\hline Mínimo & 0,03 & 0,28 & 0,34 & 8 & 18 & 53 \\
\hline \multicolumn{7}{|c|}{ Profundidade de $0,10-0,20 \mathrm{~m}$} \\
\hline Estatística & Macro & Micro & $\begin{array}{c}\text { Poros. } \\
\text { total }\end{array}$ & Argila & Areia & Silte \\
\hline Média & 0,10 & 0,40 & 0,50 & 273 & 542 & 185 \\
\hline Variância & 0,0024 & 0,0069 & 0,0106 & 1319,70 & 3370,30 & 749,40 \\
\hline $\begin{array}{l}\text { Desvio } \\
\text { padrão }\end{array}$ & 0,04 & 0,08 & 0,10 & 114,80 & 183,00 & 86,50 \\
\hline $\mathrm{CV} \% *$ & 40,00 & 20,00 & 20,00 & 42,10 & 33,90 & 46,64 \\
\hline Máximo & 0,25 & 0,55 & 0,73 & 504 & 953 & 953 \\
\hline Mínimo & 0,03 & 0,25 & 0,35 & 31 & 260 & 260 \\
\hline
\end{tabular}


Numa área cultivada, além da variabilidade natural, existem fontes adicionais de heterogeneidade no solo, por causa do manejo exercido pelo homem das mais variadas formas (SILVEIRA; CUNHA, 2002). Tais variações influenciam principalmente no acúmulo de material orgânico, no movimento de água no solo, na compactação do solo e na erosão hídrica. (CARVALHO et al. 2002). Áreas pedologicamente idênticas podem apresentar variabilidade distinta em atributos, quando submetidas às diferentes práticas de manejo. (CORÁ et al. 2004).

Verificou-se também que a variabilidade foi maior para a areia no Argissolo e a amplitude de variação no teor de argila na camada de 0,00-0,10 m foi maior (Tabela 1), provavelmente devido a sua posição no relevo (pedimento). Também se observou que à medida que se aproximava da cota mais baixa do terreno a variabilidade nos conteúdos aumentava. Na Tabela 2 têm-se os resultados da análise descritiva para a densidade do solo estudado.

Tabela 2: Estatística descritiva para os resultados de densidade do solo $\left(\mathrm{kg} \mathrm{dm}^{-3}\right)$ para os solos representativos da Microbacia Jardim Novo Horizonte, Ilha Solteira, SP.

\begin{tabular}{lcc}
\hline \multirow{2}{*}{ Estatística } & \multicolumn{2}{c}{ Latossolo Vermelho } \\
\cline { 2 - 3 } & $0,00-0,10$ & Profundidade $(\mathrm{m})$ \\
\cline { 2 - 3 } & 1,570 & $0,10-0,20$ \\
\hline Média & 0,028 & 1,630 \\
Variância & 0,168 & 0,018 \\
Desvio Padrão & 10,190 & 0,137 \\
CV\% & 1,930 & 8,400 \\
Máximo & 0,860 & 2,050 \\
Mínimo & \multicolumn{2}{c}{ Argissolo Vermelho - amarelo } \\
\hline \multicolumn{1}{c}{ Estatística } & \multicolumn{2}{c}{ Profundidade (m) } \\
\cline { 2 - 3 } & $0,00-0,10$ & $0,10-0,20$ \\
\hline Média & 1,420 & 1,450 \\
Variância & 0,053 & 0,039 \\
Desvio Padrão & 0,230 & 0,199 \\
CV\% & 16,19 & 13,720 \\
Máximo & 1,700 & 1,740 \\
Mínimo & 0,920 & 1,010 \\
\hline
\end{tabular}

A degradação do pasto e pisoteio excessivo do gado, deixando o solo exposto ou falhas, são os fatores que contribuem para a degradação das pastagens. O uso intensivo do solo ou acima de sua capacidade de suporte pode provocar mudanças indesejáveis, como aumento da densidade do solo, diminuição da porosidade e da taxa de infiltração de água. (BERTOL et al. 2004). Já para as áreas com culturas anuais, pelo fato do revolvimento do solo no momento do preparo, a taxa constante de infiltração foi maior do que nas áreas com pastagens (Tabela 2).

Para melhor compreender a densidade do solo na microbacia com dois tipos de solos com uso diferenciado foram observadas as taxas de infiltração. Para o Argissolo VermelhoAmarelo os valores das taxas constantes de infiltração foram maiores (Figura 5) comparadas ao Latossolo Vermelho, com exceção da área próxima à construção civil (Figura 6). Este fato está associado ao tipo de uso e manejo do solo; na área próxima à construção civil o solo é 
submetido à compactação por tráfego de máquinas, pessoas, aterros, o que leva ao aumento da densidade do solo.

A.

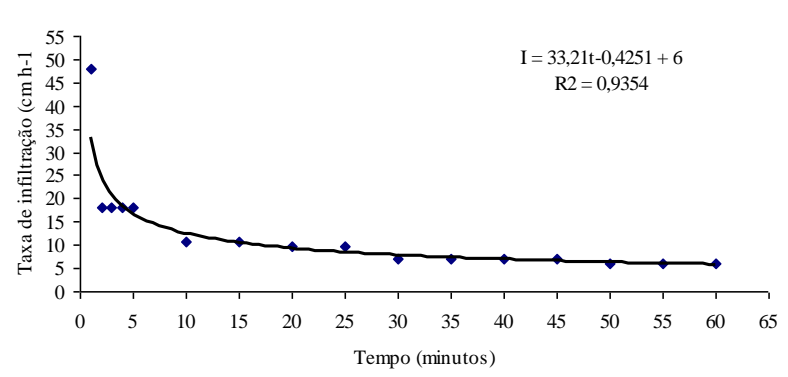

C.

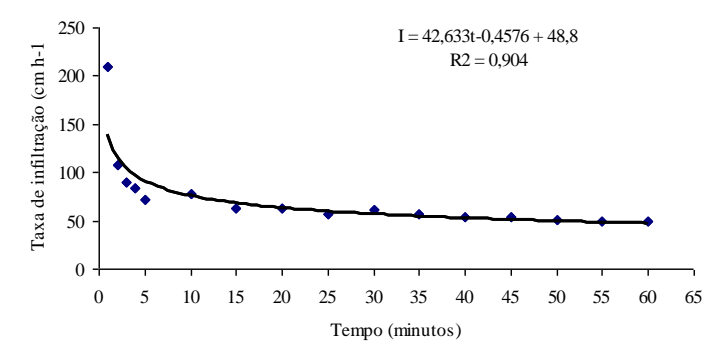

E.

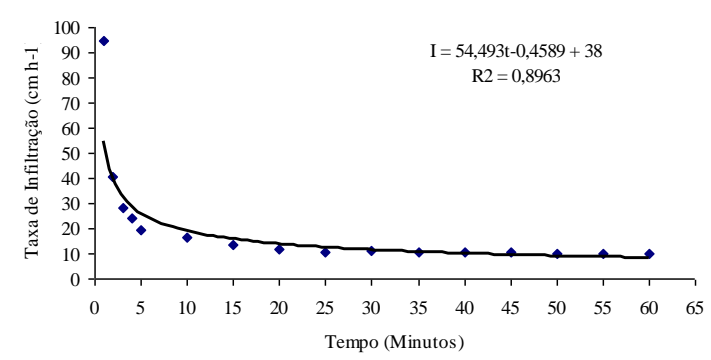

B. SILvcultura

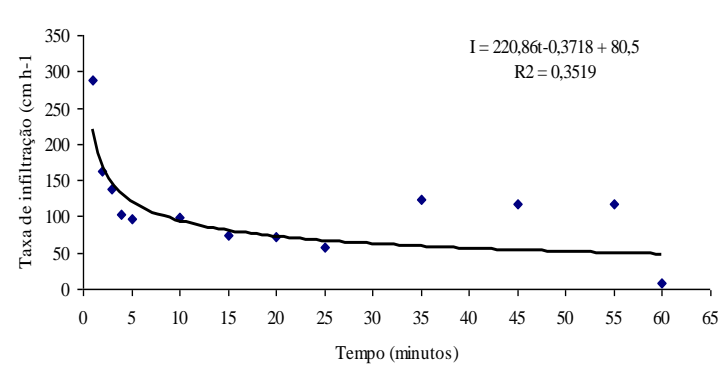

D.

HORTICULTURA

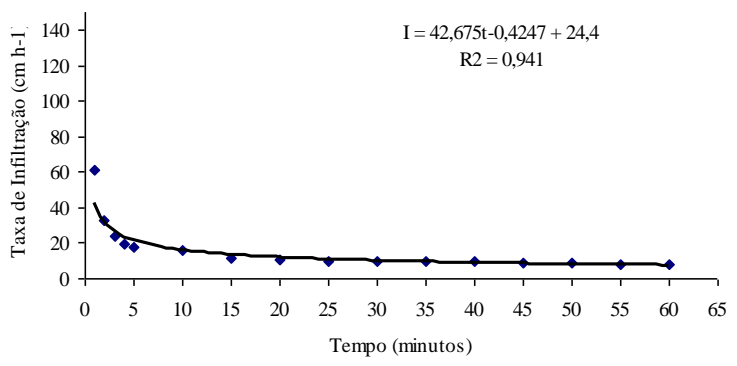

$\mathrm{F}$.

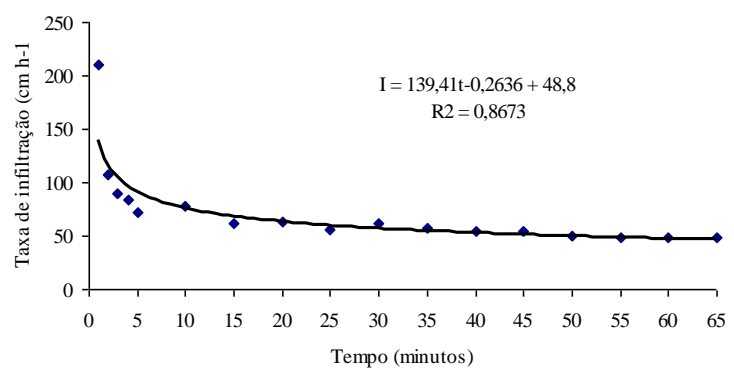

Figura: 5: Taxa de infiltração de água para o Argissolo Vermelho-Amarelo área próxima à construção civil (A), com silvicultura (B, C) e horticultura (D, E, F).

As modificações provocadas pelo revolvimento na estrutura, distribuição do tamanho dos poros e teor de carbono orgânico alteram as forças de retenção de água no solo e sua disponibilidade, os quais são fatores determinantes para o desenvolvimento de plantas em sistemas não irrigados.

O preparo modifica também a rugosidade superficial com a incorporação de resíduos vegetais ocasionando diminuição da infiltração e aumento da evaporação de água. Além do manejo, a granulometria e constituição do solo influenciam a retenção de água, pois as forças de adsorção dependem, basicamente, da espessura do filme de água que recobre as partículas, a qual varia de acordo com sua superfície específica.

Assim, a retenção de água é maior em solos argilosos e com alto teor de matéria orgânica. Neste sentido, a utilização de sistemas conservacionistas de preparo pode afetar o armazenamento de água em relação a sistemas de preparo convencional, o que tem sido 
reportado por alguns pesquisadores (SALTON; MIELNICZUK, 1995), (ROJAS; VAN LIER, 1999).

A. PASTAGEM

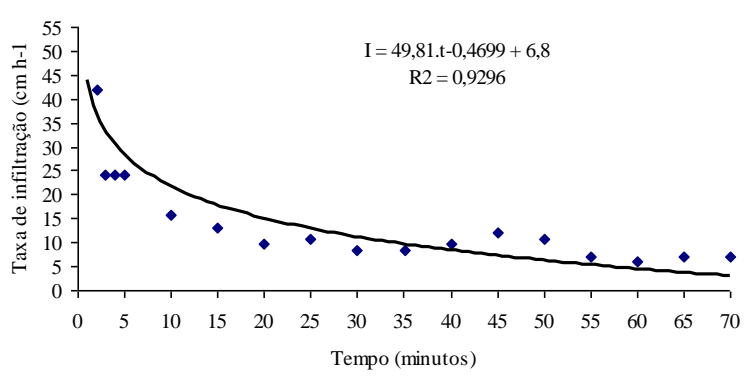

C.

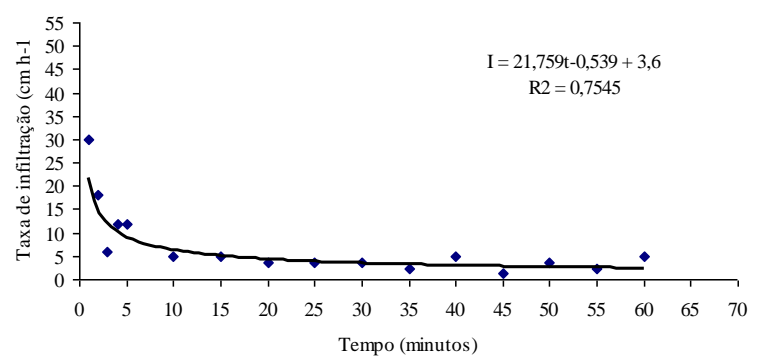

E.

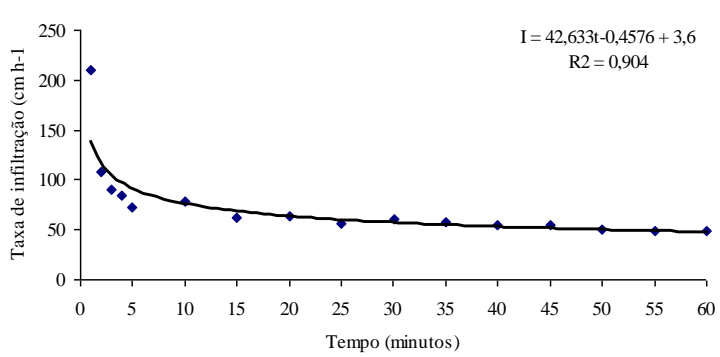

B.

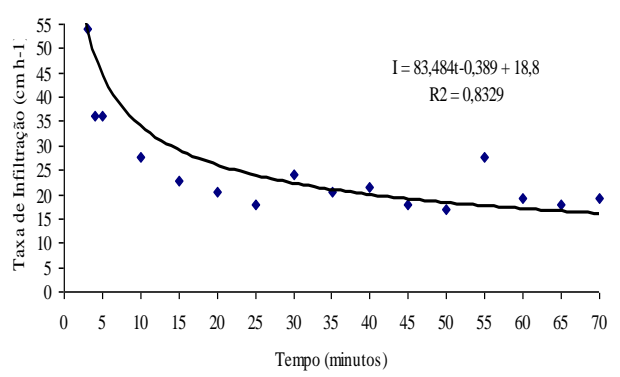

D. PASTAGEM

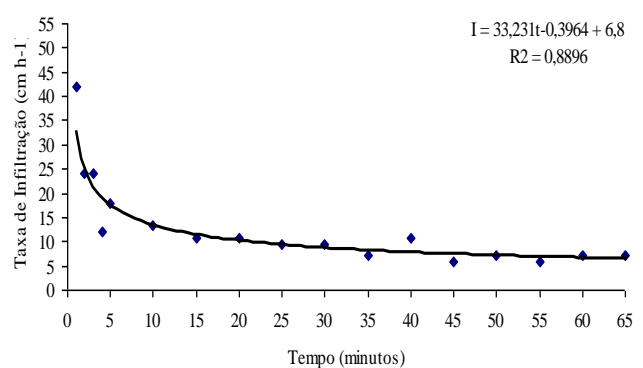

F.

PASTAGEM

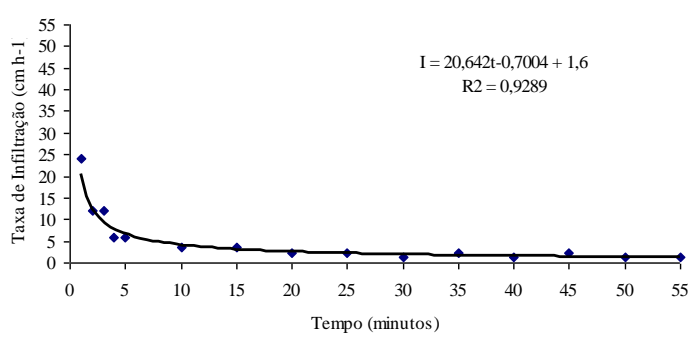

Figura 6: Taxa de infiltração de água para o Latossolo Vermelho com pastagem (A, C, D, E e F) e com cultura anual (B).

\section{CONCLUSÕES}

Os solos representativos da microbacia estudada foram: Latossolo Vermelho distrófico e Argissolo Vermelho-Amarelo eutrófico.

A variabilidade dos atributos físicos estudados foram maiores no Latossolo Vermelho comparado ao Argissolo Vermelho-Amarelo.

O Latossolo Vermelho apresentou-se com condições físicas mais degradadas tomando-se como indicadores de sua qualidade a taxa de infiltração de água e a densidade do solo. 


\section{REFERÊNCIAS BIBLIOGRÁFICAS}

ALVES, M. C.; SUZUKI, L. E. A. S.; HIPÓLITO, J. L.; CASTILHO, S. R. Propriedades físicas e infiltração de água de um latossolo vermelho amarelo (oxisol) do noroeste do estado de São Paulo, Brasil, sob três condições de uso e manejo. Revista Cuadernos Laboratório Geológico de Laxe, Coruña-Espanha, v. 30, p. 167-180, 2005.

BARCELOS, A. A; CASSOL, E. A; DENARDIN, J. E. Infiltração de água em latossolo vermelho-escuro sob condições de chuva intensa em diferentes sistemas de manejo. Revista Brasileira de Ciência do Solo, Viçosa-MG, v. 23, n. 1, p. 35-43, 1999.

BERTOL, I.; ALBUQUERQUE, J. A.; LEITE, D.; AMARAL, A. J.; ZOLDAN JÚNIOR, W. A. propriedades físicas do solo sob preparo convencional e semeadura direta em rotação e sucessão de culturas, comparadas às do campo nativo. Revista Brasileira de Ciência do Solo, Viçosa-MG, v. 28, N. 1, p. 155-163, 2004.

BERTRAND, A. T. Rate of water intake in the field. In: BLACK, C.A. (Ed.). Methods of soil analysis. Part 1. Madison-USA: American Society of Agronomy, 1965. p. 197-208.

CARVALHO, F. L. C.; COGO, N. P.; LEVIEN, R. Eficácia relativa de doses e formas de manejo do resíduo cultural de trigo na redução da erosão hídrica do solo. Revista Brasileira de Ciência do Solo, Campinas-SP, v. 14, n.1, p. 227-234, 1990.

CARVALHO, J. R. P.; SILVEIRA, P. M.; VIEIRA, S. R. Geoestatística na determinação da variabilidade espacial de características químicas do solo sob diferentes preparos. Pesquisa Agropecuária Brasileira, Brasília-DF, v. 37. n. 8, p. 1151-1159, 2002.

CORÁ, J.E.; ARAUJO, A.V.; PEREIRA, G.T.; BERALDO, J.M.G. Variabilidade espacial de atributos do solo para adoção do sistema de agricultura de precisão na cultura de cana-deaçúcar. Revista Brasileira de Ciência do Solo, Viçosa-MG, v. 28, n. 6, p. 1013-1021, 2004.

EMBRAPA. EMPRESA BRASILEIRA DE PESQUISA AGROPECUARIA Manual de métodos de análise de solo. 2. ed. Rio de Janeiro-RJ: EMBRAPA/CNPSO, 1997. p. 212.

GREENLAND, D. J. Soil structure and erosion hazard. In: GREENLAND, D. J.; LAL, R. Soil conservation and management in the humid tropics. New York-USA: John Wiley e Sons, 1977. p. 17-23.

HERNANDEZ, F. B. T.; LEMOS FILHO, M. A. F.; BUZETTI, S. Software HIDRISA e o balanço hídrico de Ilha Solteira. Ilha Solteira: UNESP/FEIS/Área de Hidráulica e Irrigação, 1995. 45p.

ROCHA, J. S. M. Manual de projetos ambientais. Santa Maria-RS: Imprensa Universitária, 1997. $423 \mathrm{p}$.

ROCHA, J. S. M.; DALTROZO, C. C. Florestamentos compensatórios para retenção de água em microbacias. Revista Educação Agrícola Superior, v. 23, n. 1, p. 71-75, 2008.

ROJAS, C. A. L.; VAN LIER, Q. J. Alterações físicas e hídricas de um Podzólico em função de sistemas de preparo. Pesquisa Agropecuária Gaúcha, Porto Alegre-RS, v. 5, n. 1, p. 105$115,1999$.

ROSOLEM, C. A.; VALE, L. S. R.; GRASSI FILHO, H.; MORAES, M. H. Sistema radicular e nutrição do milho em função da calagem e da compactação do solo. Revista Brasileira de Ciência do Solo, Campinas-SP, v.18, n. 3, p.491-497, 1994 
SALTON, J. C.; MIELNICZUK, J. Relações entre sistemas de preparo, temperatura e umidade de um Podzólico Vermelho Escuro de Eldorado do Sul (RS). Revista Brasileira de Ciência do Solo, Viçosa-MG, v. 19, n. 1, p. 313-319, 1995.

SANTOS, G. V.; DIAS, H. C. T.; SILVA, A. P. S.; MACEDO, M. N. C. Análise hidrológica e socioambiental da bacia hidrográfica do Córrego Romão dos Reis, Viçosa-MG. Revista Árvore, v. 31, n. 5, p. 931-940, 2007.

SILVEIRA, P. M.; CUNHA, A. A. Variabilidade de micronutrientes, matéria orgânica e argila de um latossolo submetido a sistemas de preparo. Pesquisa Agropecuária Brasileira, Brasília-DF, v. 37, n. 9, p. 1325-1332, 2002.

SMITH, R.E. The infiltration envelope: results from a theoretical infiltrometer. Journal of Hydrology. Melbourne, v. 17, n. 1-2, p. 1-22, 1972.

SOANE, B. D.; OUWERKERK, C. V. Soil compaction problems in world agriculture. In: SOANE, B. D.; OUWERKERK, C. V. (Eds). Soil compaction in crop production. Amsterdam-HO: Elsevier, 1994. p. 01-21.

VIEIRA, S. R.; NIELSEN, D. R.; BIGGAR, J. W. Spatial variability of field-measured infiltration rate. Soil Science Society of America Journal, v. 45, n. 8, p. 1040-1048, 1981.

WARRICK, A. W.; NIELSEN, D. R. Spatial variability of soil physical properties in thefield.

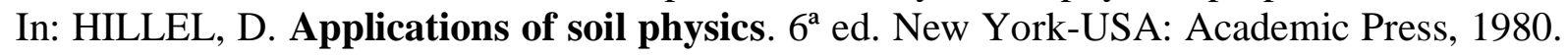
p. $70-110$. 